\title{
Metal-induced neurodegeneration in C. elegans
}

\section{Pan Chen ${ }^{1}$, Ebany J. Martinez-Finley ${ }^{1}$, Julia Bornhorst ${ }^{1}$, Sudipta Chakraborty ${ }^{1}$ and Michael Aschner ${ }^{1,2 *}$}

\author{
Department of Pediatrics, Vanderbilt University Medical Center, Nashville, TN, USA \\ 2 Department of Pharmacology, the Kennedy Center for Research on Human Development, and the Center for Molecular Toxicology, Vanderbilt University Medical \\ Center, Nashville, TN, USA
}

Edited by:

Anthony R. White, The University of

Melbourne, Australia

Reviewed by:

Marcelo Farina, Universidade

Federal de Santa Catarina, Brazil

Gawain McColl, The Florey Institute

of Neuroscience and Mental Health,

Australia

*Correspondence:

Michael Aschner, Division of

Pediatric Toxicology, Vanderbilt

University Medical Center, 11425

MRB IV, 2215B Garland Avenue,

Nashville, TN 37232-0414, USA.

e-mail:michael.aschner@

vanderbilt.edu
The model species, Caenorhabditis elegans, has been used as a tool to probe for mechanisms underlying numerous neurodegenerative diseases. This use has been exploited to study neurodegeneration induced by metals. The allure of the nematode comes from the ease of genetic manipulation, the ability to fluorescently label neuronal subtypes, and the relative simplicity of the nervous system. Notably, C. elegans have approximately $60-80 \%$ of human genes and contain genes involved in metal homeostasis and transport, allowing for the study of metal-induced degeneration in the nematode. This review discusses methods to assess degeneration as well as outlines techniques for genetic manipulation and presents a comprehensive survey of the existing literature on metal-induced degeneration studies in the worm.

Keywords: neurodegeneration, behavior, metals, C. elegans, neurotransmitters

\section{INTRODUCTION}

The simplicity of the small nematode Caenorhabditis elegans (C. elegans) makes it a suitable model organism for biomedical research. Compared with mammalian models, it has a number of advantages that makes it a powerful tool for studies on human disease. First, $60-80 \%$ of human genes have corresponding genes in C. elegans, depending on the specific bioinformatic methods used (Titus and Michael, 2006). Many genetic factors causing human diseases have corresponding worm homologs, allowing for mechanism-based studies. Second, the small size and the fast life-cycle of the worm allow for easy maintenance. The adult worm is only $1.3 \mathrm{~mm}$ long and it takes 3 days for an embryo to reach adulthood and reproduce. A $100 \mathrm{~mm}$ petri-dish can accommodate thousands of self-fertilizing nematodes within couple of days. This is particularly important for pharmaceutical drug screens. Third, C. elegans are transparent, which allows in vivo study with fluorescent reporters, such as green and red fluorescent proteins. This has been widely used to study axon guidance, neurodegeneration, endocytosis and fat metabolism in living worms. Fourth, the simple, but complete nervous system makes it easy to investigate neurological function in C. elegans. Although a worm has only 302 neurons, it shares similar neurotransmitters with humans, including dopamine (DA), acetylcholine (ACh), serotonin (5-HT), gamma-aminobutyric acid (GABA), glutamate, and others. Fifth, a variety of tools are available in C. elegans. The genome and cell line lineage have been completely mapped, RNA interference (RNAi) libraries are able to knock down 90\% of genes, a large pool of knockout mutants are available from the C. elegans genetic center (CGC) and commercial worm-specific microarray probes have been developed.

A big advantage afforded by $C$. elegans as a model for studies on human neurological diseases is the simplicity of its nervous system: the worm contains 302 neurons and about 5,000 synapses
(White et al., 1986). Despite this simplicity, C. elegans has a complete nervous system with four functional categories of neurons based on their circuitry: (1) motor neurons, which pass synaptic signals to muscle cells; (2) sensory neurons, which convert environmental signals into internal stimuli; (3) interneurons, which receive and deliver signals between neurons; and (4) polymodal neurons, which have two or more of the functions described above. Most commonly, studies are performed on different types of neurons based on their neurotransmitter profile.

The biosynthesis and transport of neurotransmitters are conserved in the nematode and human nervous system. Among different types of neurons, dopaminergic (DAergic) and gammaaminobutyric acid (GABA-ergic) neurodegeneration are the two best characterized. DAergic neuron death is a well-known feature of Parkinson's disease (PD). C. elegans hermaphrodites have eight DAergic neurons; two pairs of cephalic (CEP) neurons, a pair of anterior deirid (ADE) neurons, and a pair of postdeirid (PDE) neurons (WormAtlas, 2002, 2003, 2004, 2005, 2006, 2007, 2008, 2009; Toth et al., 2012; WormBase, 2013). Since their genome has been fully characterized it is also known that they contain all genes responsible for DA biosynthesis, packaging and reuptake (Sulston et al., 1975; Jayanthi et al., 1998). Male C. elegans have additional DAergic neurons (Sulston et al., 1975). DA signaling is important in mediating learning and locomotion behavior (Sawin et al., 2000). DA is also a requirement for olfactory adaptation (Colbert and Bargmann, 1995). The role of DA in modulation of locomotor activity has been exploited to study DAergic degeneration. Using green fluorescent protein (GFP) (Nass et al., 2002; Cao et al., 2005) or mCherry protein (Harrington et al., 2012) to visualize DAergic neurons in C. elegans, researchers are able to monitor neurodegenerative processes in living animals. Many known causes of PD also result in DAergic neurodegeneration in C. elegans, including aberrant proteins [alpha-synuclein (Cao 
et al., 2005; Harrington et al., 2012)], heavy metals [i.e., manganese (Mn) (Benedetto et al., 2010), methylmercury (MeHg) (VanDuyn et al., 2010), aluminum (VanDuyn et al., 2013)], and environmental contaminants [i.e., fungicides (Harrison Brody et al., 2013), pesticides (Negga et al., 2012), insecticides (Mocko et al., 2010), 1-methyl-4-phenylpyridinium $\left(\mathrm{MPP}^{+}\right)(\mathrm{Pu}$ and Weidong, 2008; Mocko et al., 2010), and 6-hydroxydopamine (6-OHDA) (Cao et al., 2005; Ruan et al., 2010)]. The DAergic neurons are mechanosensory and defects or loss of these neurons results in behavioral changes in response to environmental stimuli (i.e., food sensing).

In vertebrates, GABA is the most abundant neurotransmitter in inhibitory synapses in the central nervous system (CNS), while in nematodes, GABA is used as both an inhibitory and excitatory neurotransmitter primarily at neuromuscular synapses, as worms do not have a CNS. GABAergic neurons in the nematode consist of 26 neurons that are categorized under six classes, DD, VD, RME, RIS, AVL, and DVB, based on their synaptic outputs. $\mathrm{DD}$ and VD innervate the dorsal and ventral body muscles, RME innervate the head and AVL and DVB innervate the enteric muscles and RIS are interneurons (White et al., 1986). Worms defective in GABAergic function exhibit "shrinking" behavior, whereby the nematode simultaneously hypercontracts both ventral and dorsal body muscles, as well as abnormal defecation and foraging. unc-25 encodes the GABA enzyme glutamic acid decarboxylase and $u n c-47$ encodes the GABA vesicular transporter (McIntire et al., 1997; Jin et al., 1999). unc-30 encodes a homeodomain protein of the Pitx family and regulates the differentiation of the D-type GABAergic neurons (Jin et al., 1994). Overexpression of genetic risk factors associated with Alzheimer's disease (AD) [tau (Kraemer et al., 2003; Miyasaka et al., 2005; Brandt et al., 2009)] and Amyotrophic lateral sclerosis (ALS) [TDP-43 and FUS (Vaccaro et al., 2012)], as well as exposure to several heavy metals [lead $(\mathrm{Pb})$, mercury $(\mathrm{Hg})$, copper $(\mathrm{Cu})$, chromium $(\mathrm{Cr})$, and Mn (Du and Wang, 2009; Xing et al., 2009b)] results in GABAergic neurodegeneration in nematodes. The loss or injury of GABAergic neurons alters locomotion (McLntire et al., 1993), foraging (White et al., 1986) and defecation (McLntire et al., 1993) behaviors, which may be used to monitor the integrity of GABAergic neurons.

In addition to DAergic and GABAergic neurons, neurodegeneration has also been studied in cholinergic neurons. In C. elegans, $\mathrm{ACh}$ is the major excitatory neurotransmitter, which directly or indirectly regulates locomotion (crawling and swimming) (Mullen et al., 2007), egg laying (Bany et al., 2003), pharyngeal pumping (McKay et al., 2004), defecation cycling (Thomas, 1990), and male mating (Liu and Sternberg, 1995). Gain-offunction nicotinic ACh receptor acr-2 (Barbagallo et al., 2010) and selenium (Se) (Estevez et al., 2012) are both able to induce cholinergic motor neuron degeneration and paralysis in worms.

Another neurotransmitter, serotonin (5-HT), is synthesized in eight types of neurons and regulates locomotion, defecation, egg laying, male mating and pharyngeal pumping in worms (Mendel et al., 1995; Segalat et al., 1995; Weinshenker et al., 1995; Niacaris and Avery, 2003). The basal slowing response and egg laying assay have been well-characterized in studies on 5-HT signaling. Mutants for 5-HT enzymes, bas-1 and cat-4 (both involved in
5-HT and DA biosynthesis), have been used to analyze serotoninmediated behaviors (Loer and Kenyon, 1993; Waggoner et al., 1998; Sawin et al., 2000). The locomotor behaviors have been used most often for analysis of neurodegeneration and application of exogenous 5-HT inhibits locomotion, but stimulates egg-laying and pharyngeal pumping (Horvitz et al., 1982; Segalat et al., 1995; Weinshenker et al., 1995; Sawin et al., 2000; Rogers et al., 2001; Niacaris and Avery, 2003). In many of the worm behavioral assays it is difficult to determine the effects of DA vs. 5 -HT. Degeneration of other types of neurons induced by metal exposure is less studied in worms, thus not discussed here.

Finally, glutamate is important in synaptic transmission, plasticity and disease, with excitotoxicity, inflammation, oxidative stress, and mitochondrial dysfunction implicated in ALS. Excitatory and inhibitory ionotropic glutamate receptors (iGluRs) mediate some behavior and approximately 10 putative iGluR subunits are expressed in C. elegans ( $g l r 1-8$ and $n m r$ 1-2) (Brockie et al., 2001). Six of the subunits, including $g l r-1, g l r-2$, $g l r-4, g l r-5, n m r-1$, and $n m r-2$, are expressed in many of the $C$. elegans interneurons. GLR-1 in particular has been linked to mediating the avoidance of hyperosmotic stimuli (Mellem et al., 2002), control of forward and backward movement (Brockie et al., 2001), foraging behavior (Hills et al., 2004), and long-term memory (Rose et al., 2003). There is also conserved sequence and function of the vesicular glutamate transporter (eat-4) (Lee et al., 1999), and other glutamate transporters (glt-1; glt-3-7) (Mano et al., 2007).

In summary, $C$. elegans provides a valuable research tool to study the mechanisms of metal induced human neurological disorders by permitting the visualization of different types of neurons and assessment of their function by florescence labeled cell bodies and functional behavior assays, respectively.

\section{TECHNIQUES FOR STUDYING NEURODEGENERATION IN C. elegans}

Conserved neurotransmitter biology and high homology with mammalian systems make C. elegans a unique system for studies on neurodegenerative disease. The processes of synaptic release, trafficking and formation of neurotransmitters are also conserved. Methods to study neurotoxicologic endpoints have included examining the morphology, behaviors, and changes in gene expression and neurotransmitters.

\section{TOOLS FOR ASSESSING NEURONAL STRUCTURE \\ Fluorescently tagged neurons and microscopy}

Contributing to the investigative value of this species is the transparency of the worm, allowing for in vivo visualization of fluorescently labeled neurons. Cell bodies and individual processes can be visualized in vivo in the worm. Morphological changes, characterized by puncta, blebs, neuronal absence or shrinkage, presence of vacuoles, dorsal or ventral cord gaps, loss of cell bodies or strand breaks in neuronal processes can be used as indicators of neurodegeneration (Nass et al., 2002; Martinez-Finley and Aschner, 2011). GFP has frequently been employed as a reporter construct to visualize specific neurons and synapses in $C$. elegans. DAergic neurons have been tagged for visualization most frequently through the dat-1::GFP reporter (Helmcke et al., 2010; 
VanDuyn et al., 2010), serotonergic neurons through tph-1::GFP (Sze et al., 2000; Nass et al., 2002), GABAergic neurons through unc-25::GFP (Cinar et al., 2005), and cholinergic neurons through unc-1::GFP (Winnier et al., 1999; Nass et al., 2002), and glutamatergic neuron through eat-4::GFP (Lee et al., 1999; Earls et al., 2010). Reporter gene fusions also allow for visualization of neuronal morphology and protein expression patterns. Visualization of the neurons is useful, but it is important to correlate the structural damage with cellular and molecular changes as quenching of GFP fluorescence is a possibility and can result in false data interpretation. Both confocal and standard fluorescence microscopy have been used to visualize fluorescently tagged neurons. Electron microscopy has also been used historically to measure structural integrity and fluorescence-activated cell sorting (FACS) has been utilized for purification.

\section{TOOLS FOR ASSESSING NEURONAL FUNCTION Behavioral assays}

C. elegans behavior is used as a reliable and sensitive measure of the function of neurons as the behaviors are sensitive to underlying cellular and molecular alterations. There are a large variety of behavioral tests in C. elegans to assay neurodegeneration. There are nematode equivalents of mammalian DAergic, serotonergic, cholinergic, GABAergic and glutamatergic neurons (see above) and high homology exists between the two systems. A number of behaviors can be assayed to determine the function of the cholinergic and glutamatergic neurons, but these behaviors have not been extensively studied in regards to metals and neurodegeneration, and therefore are not included in this review [for a review see (WormBase, 2013)]. Many of the assays listed below have been designed to assess DA, 5-HT and GABA subtypes.

\section{Basal slowing response}

Bacterial mechanosensation induces the DA-mediated slowing of locomotion in the presence of food (bacteria), and can be measured by counting the number of body bends per 20-s interval (Sawin et al., 2000). Locomotor rates are compared between the well-fed worms placed on plates of food vs. those placed on plates without food and the measurement is referred to as the change $(\Delta)$ in body bends over a set period of time. A lower value represents less slowing on food and therefore deficits in DAergic function as worms deficient in DA do not slow their locomotion in the presence of food. The cat-2 strain is tyrosine hydroxylase (TH)-deficient and therefore defective in bacterial mechanosensation, making it a positive control (Sawin et al., 2000). Proper controls for the assay include well-fed nematodes and consistency in the size and thickness of the bacterial lawn in all plates used. Bas- 1 and cat-4 mutants also do not slow in response to the bacterial lawn (Sawin et al., 2000). Application of exogenous serotonin can rescue the behavior in bas-1 and cat- 4 mutants. In this assay the key to parsing out 5-HT effects from DA effects is the state of the worms; the 5-HT version of this task requires starved worms, while the DA version requires that the worms be well-fed.

\section{Ethanol preference}

Ethanol preference in C. elegans requires DA and serotonin. This has been shown using cat 2 and tph-1 mutants as these worms do not show a normal wildtype response in the ethanol preference task (Lee et al., 2009). In this assay young adult worms are preincubated on a seeded control or ethanol plate. After an incubation period the worms are removed from the preincubation plates and placed on assay plates. Assay plates are divided into quadrants, with two quadrants laced with ethanol and the other without. Worms are placed at an origin point of an assay plate and allowed to move for $30 \mathrm{~min}$ at which point they are scored for their quadrant of preference. A preference index (PI) is calculated as [(number of worms in ethanol quadrants) - (number of worms in control quadrants)]/Total number of worms tested (Lee et al., 2009). Worms with functional DA and 5-HT develop ethanol preference whereas mutant worms do not.

\section{Area-restricted searching (ARS)}

This task capitalizes on the fact that worms must have functional DA in order to search for food. Wildtype worms that have consumed and exhausted the immediate food source will expand their search to surrounding areas. This behavior is measured by time-dependent reduction in turning frequency after the last food encounter. After a short time if the worm cannot find more food in the immediate area, the frequency of high-angled turns is reduced and the animal begins to explore more distant areas. Functional DA is required for ARS as ablation of dopaminergic neurons eliminates ARS behavior and preincubation with DA restores the ARS behavior in worms with defective DA (Hills et al., 2004). The glutamatergic neurons also participate in this behavior as glutamate receptor mutants exhibit problems with the ARS behavior (Hills et al., 2004).

\section{Habituation task/tap withdrawal response}

Functional DA allows worms to alter their behavior in the tapping task. Nematodes respond to a mechanical stimulus (plate tapping) by accelerating their forward locomotion rate or by swimming backwards. Repeatedly tapping of the plate results in worms habituating to the stimulus and decreasing the frequency of their reversals. What is measured is the time that it takes to habituate to the tapping rather than whether or not the worm responds to the tapping. All worm strains tested in this task are able to reduce their reversal rates but the distinguishing factor of whether DAergic neurons are functional or dysfunctional is the lag time in response. Intertapping interval is also an important consideration in this assay. cat-2 mutant worms habituate to tap faster than wildtype worms and this response can be rescued by pre-exposing mutants to exogenous DA (Groves and Thompson, 1970; Broster and Rankin, 1994; Rose and Rankin, 2001; Sanyal et al., 2004).

\section{Pharyngeal pumping and thrashing behaviors}

Pharyngeal pumping and thrashing rates are controlled by various mechanisms in the nematode. The pharynx is responsible for feeding via rhythmic contractions. Age-related decline in pharyngeal pumping rate has been described in C. elegans and is correlated with a decline in survival probability and body movement decline. Pumps per minute are manually counted using a dissecting microscope to assess pharyngeal pumping rate. The maximum pumping rate of the pharynx is $\sim 300$ pumps per 
minute (in adults that are at least 2 days old). Thrashing behavior is a common test in C. elegans for measuring motility. Thrashing behavior is assessed by videotaping nematodes that are placed in $\sim 10 \mu \mathrm{L}$ of water on a transparent plate with shallow, concave wells. A thrash is a change in direction in midbody bending. A body bend is counted as a change in the direction of the posterior bulb of the pharynx. There are multiple programs used to assess this behavior including Worm Tracker, Nemo, Parallel Worm Tracker, OptoTracker, Multimodal illumination, and tracking system, CoLBeRT, many of which use MATLAB, JAVA, or LabVIEW software to quantify movement (WormBase, 2013). This assay, along with visualization of the neurons, has been used to assess GABAergic function after lead or mercury exposure (Helmcke et al., 2009; Xing et al., 2009b).

\section{MEASUREMENT OF NEUROTRANSMITTERS}

The neurotransmitters, DA and serotonin, and neuromodulators, octopamine and tyramine, can all be detected in C. elegans extracts by high-performance liquid chromatography (HPLC) (Sulston et al., 1975; Horvitz et al., 1982; Sanyal et al., 2004; Alkema et al., 2005). Thousands of worms (over $30 \mathrm{ul}$ of packed worms) must be used for HPLC analysis and the worms must be washed several times to avoid bacterial contamination (Sulston et al., 1975; Horvitz et al., 1982; Sanyal et al., 2004; Alkema et al., 2005).

\section{USING C. elegans AS A MODEL OF NEURODEGENERATION: MODIFYING GENETICS}

The C. elegans model system has become a popular and innovative tool in advancing mechanistic studies concerning various neurodegenerative processes. The generation of genetic knockouts and knockdowns can be achieved rapidly in nematodes due to their quick life cycle and short lifespan. Classical forward genetics studies involve treating organisms with mutagens to induce DNA mutations followed by isolation of individuals with atypical phenotypes of interest. Reverse genetics allows the opposite strategy by altering a specific gene in order to study its function and the role it may play in various processes and pathways. RNA interference (RNAi) and transgenesis, which can be accomplished using microinjection and gene bombardment techniques are also tools for achieving gene knockdown.

\section{Microinjection}

This approach uses a microinjection needle to introduce a plasmid carrying the gene of interest into the cytoplasmic core of distal gonad arms in a hermaphrodite worm, allowing the delivery of the plasmid to several germ cell nuclei and the production of extrachromosomal DNA arrays (Ahringer, 2006). The simplest approach to transgenesis typically involves microinjecting a plasmid that contains a cloned $5^{\prime}$ regulatory sequence of the gene of interest fused to a reporter gene whose activity can then be assayed; a 3' UTR should also be included (Praitis and Maduro, 2011). As the worm is fully transparent, it is usually desired to fuse genes of interest to a fluorescent reporter whose intensity can then be imaged, such as GFP, yellow fluorescent protein (YFP), or m-cherry (Miller et al., 1999). There are also sequences specific for subcellular targeting that can be included in the plasmids, such as a nuclear localization signal (NLS) for nuclear targeting or a mitochondrial targeting sequence (MTS) for mitochondrial localization. Similarly, tissue or cell-specific expression can also be studied using transgenes that are directed by tissue or cellspecific promoters (Praitis and Maduro, 2011). Additionally, it is typical to include a coinjection marker (antibiotic resistance, tissue-specific fluorescent promoter, etc.) to follow the transgene through the transformation process in larvae and subsequent crossing. However, this is not always necessary if the transgene containing the gene of interest includes a marker itself that can be conveniently distinguished from non-transgenic worms (e.g., a bright GFP reporter).

Following microinjection of transgenes, the DNA arrays produced are extrachromsomal and are not fully integrated into the genome (Ahringer, 2006). Without integration, the arrays remain unstable and can be lost through successive generations. Gamma or UV irradiation or exposure to chemical mutagens can induce integration of the arrays into chromosomes. A small population of the transformed nematodes is mutagenized, resulting in several F1 animals that produce the F2 generation that can then be assayed for $100 \%$ transmission of the transgene. Integration of the original transgene is vital for any further genetic manipulation of the transformed lines, eventually allowing multiple transgenes to be incorporated into the same strain (Praitis and Maduro, 2011). As with most genetic manipulations, integrated strains should be backcrossed several times in order to remove any mutations introduced into the genome from the integration process.

However, high copies of the transgene in the extrachromosomal array can lead to undesirable expression of the transgene, ranging from increased transgene expression relative to the targeted endogenous gene to gene silencing from tandem repeat sequences present in the array. For this reason, another method of transgenesis uses microparticle bombardment. Biolistic transformation allows for direct insertion of transgenes into the chromosome, especially with a low-copy number that becomes fully integrated. Bombardment is usually done with the DNAcoated gold beads that are then bombarded onto L4 and adult hermaphrodites. This technique revolves around the ability of DNA to form a complex with gold particles in the presence of $\mathrm{CaCl}_{2}$, where the DNA itself is protected from degradation by using cationic polyamines (e.g., spermidine) (Isik and Berezikov, 2013). Researchers have also found that this "gene gun" technique not only reproducibly allows for invariable expression levels and patterns that are difficult to obtain with extrachromosomal arrays, but that low-copy transgene expression does not get silenced in the germline (Praitis et al., 2001). Newer techniques to allow single- or low-copy transgene expression without bombardment are in the process of development, including the use of ultraviolent trimethylpsoralen (Kage-Nakadai et al., 2012).

\section{RNA interference (RNAi)}

This methodology involves the exogenous introduction of double-stranded RNA (dsRNA) that is complementary to a specific sequence of the gene of interest into the model organism, resulting in the activation of an endogenous cellular pathway that causes significantly decreased expression of that gene. This technique is advantageous in the $C$. elegans system and is dependent 
on RNA-dependent RNA polymerases (RdRPs) (Simmer et al., 2002); unlike mammals, RNAi is actually heritable in nematodes, as the systemic gene knockdown can persist in the progeny.

RNAi effect can be achieved in three ways: (1) by microinjection of a dsRNA sequence complementary to the gene of interest into the body cavity, including the gonad and intestine, (2) by soaking worms in a dsRNA-containing solution, and (3) by feeding worms with E. coli expressing the dsRNA of interest (Tabara et al., 1998).

The unique, highly systemic nature of RNAi in C. elegans is thought to occur due to a rapid transport of dsRNA from cell to cell through the SID-1 channel. This transmembrane protein allows for passive, bidirectional transport to cells that do not initially receive the dsRNA delivery, and is selectively gated by the presence of dsRNA (Shih and Hunter, 2011). Wildtype N2 strains are sufficient in producing knockdowns using RNAi; however, some RNAi-hypersensitive strains can be necessary to increase the knockdown strength and phenotype penetrance. These strains include $r r f-3$, eri-1, and lin-15B. rrf-3 is a C. elegans RNA-dependent RNA polymerase (Simmer et al., 2002), while eri-1 (enhanced RNAi) is a $3^{\prime}-5^{\prime}$ exoribonuclease that negatively regulates RNAi (Kennedy et al., 2004) and lin-15B is important in cell differentiation and negatively regulates vulval development, as well as RNAi (Wang et al., 2005). There are currently two commercially available RNAi feeding libraries. The Ahringer lab library contains about 16,757 clones that were constructed from cloning gene-specific genomic sequences between two T7 promoters. The Vidal lab library contains 11,511 clones and was made by the Gateway cloning system that clones full-length open reading frames (ORF) templates into double $\mathrm{T} 7$ vectors. Together, these libraries cover approximately $94 \%$ of the C. elegans genome (Ahringer, 2006; Antoshechkin and Sternberg, 2007).

\section{Gene knockout}

In comparison to RNAi-mediated gene knockdown, knockout in C. elegans was made simple by the development of the MosDel system, or Mos-mediated deletion. A plasmid containing Mos1 is delivered to a DNA strand that is next to the target gene, causing a break in that strand. Upon induction of cellular DNA damage repair mechanisms, a DNA template that lacks the targeted gene of interest is introduced and matches the sequence of the broken DNA strand (Frokjaer-Jensen et al., 2010). Thus, this technique tricks the cell into knocking out the gene by repairing the original double-strand break with a DNA template that does not contain the gene of interest. Large-scale projects have aimed to utilize the MosDel system to create large libraries of transposon-tagged alleles (Bazopoulou and Tavernarakis, 2009). Prior to the development of this method, knockouts were primarily generated using random chemical mutagenesis (i.e., EMS mutagenesis) to create loss-of-function mutants that were then screened using gene-specific primers for random deleted regions in targeted genes. However, with this technique there is the possibility of random background mutations and it is not as specific as the MosDEL system. The commercial availability of deletion mutants is possible through the C. elegans Gene Knockout Consortium (GKC) and the National BioResource Project of Japan (NBRP), both of whom send their isolated deletion mutants to the Caenorhabditis Genetics Center (CGC) for distribution (Antoshechkin and Sternberg, 2007).

\section{MECHANISMS OF NEURODEGENERATION INDUCED BY METAL Aluminum (AI)}

$\mathrm{Al}$ is one of the most abundant metal elements in the Earth's crust and exposure to bioavailable Al may be significant owing to its ubiquitous presence in soil and fertilizers, cookware, and pharmaceutical and cosmetic preparations (Verstraeten et al., 2008). Although the physiological requirement for $\mathrm{Al}$ has yet to be defined, it has been posited that $\mathrm{Al}$ may have an etiopathogenic role in neurodegenerative diseases (Halatek et al., 2005). Studies with $\mathrm{Al}$ in the form of $\mathrm{AlCl}_{3}, \mathrm{Al}\left(\mathrm{NO}_{3}\right)_{3}$, or $\mathrm{Al}_{2}\left(\mathrm{SO}_{4}\right)_{3}$ identified phenotypic abnormalities, including toxic effects on lifespan, body size, development, reproduction, locomotion, behavioral plasticity, and memory in the worm (Wang et al., 2009; Page et al., 2012). Additionally, Page et al. showed changes in elemental composition of whole worms exposed to $\mathrm{Al}$, noting a significant increase in multiple metals and ensuing oxidative stress $(\mathrm{Ba}, \mathrm{Fe}, \mathrm{Cr}$, and $\mathrm{Cu})$, hypothesizing that altered levels of these elements contributed to the aforementioned phenotypes seen in chronic Al toxicity (Page et al., 2012).

VanDuyn et al. addressed molecular attributes of Al-induced DA neurodegeneration in C. elegans (VanDuyn et al., 2013). A brief exposure to $\mathrm{Al}$ decreased mitochondrial membrane potential and cellular ATP levels and led to DAergic neurodegeneration, which was dependent upon SMF-3, a homolog to the human divalent metal transporter (DMT1). Al exposure significantly decreased SMF-3 protein levels and exacerbated DAergic neurodegeneration in the presence of human $\mathrm{PD}$-associated protein $\alpha$-synuclein, Nrf2/SKN-1 and Apaf1/CED-4. Deletion of SMF-3 conferred resistance to $\mathrm{Al}$ due to sequestration of $\mathrm{Al}$ in an intracellular compartment (VanDuyn et al., 2013). Neuroprotection was also reported by Ye et al. showing that a treatment with trace vitamin $\mathrm{E}$ could ameliorate memory deficits in $\mathrm{Al}$ exposed worms (Ye et al., 2008).

The acute and chronic effects of $\mathrm{Al}_{2} \mathrm{O}_{3}$ nanoparticles (NPs) in C. elegans have been recently addressed (Yu et al., 2011; Li et al., 2012). Acute toxicity was associated with increased lethality and altered growth, reproduction and stress responses, whereas chronic toxicity led to increased oxidative stress. Li et al. noted decreased locomotion behaviors in nematodes chronically exposed to $\mathrm{Al}_{2} \mathrm{O}_{3}$-nanoparticles (NPs) concomitant with increased reactive oxygen species (ROS) generation and disruption of ROS defense mechanisms, secondary to the suppression of Mn-SODs (Li et al., 2012).

\section{Copper (Cu)}

The essential trace element $\mathrm{Cu}$ serves as a cofactor in many critical biological processes such as in iron $(\mathrm{Fe})$ homeostasis (ceruloplasmin), catecholamine biosynthesis (tyrosinase, dopamine-b-hydroxylase), oxidative phosphorylation (cytochrome c oxidase), and oxidative stress protection (superoxide dismutase) (Arredondo and Nunez, 2005). Therefore, $\mathrm{Cu}$ deficiency or overload may result in multiple pathologies, including irreversible CNS damage (Prohaska, 
2000; Taly et al., 2007; Diaz-Veliz et al., 2008). In C. elegans, $\mathrm{Cu}$ deficiency led to decreased $\mathrm{Cu} / \mathrm{Zn}$ superoxide dismutase (SOD), reducing defenses against oxidative stress (Yang et al., 1998). Exposure to excess $\mathrm{CuSO}_{4}$ induced detrimental effects on brood size and life span, an increase in generation time and impaired development (Harada et al., 2007; Calafato et al., 2008). PD worms expressing $\alpha$-synuclein or lacking parkin do not show increased sensitivity to $\mathrm{Cu}$ toxicity (Ved et al., 2005). In the context of $\mathrm{AD}, \mathrm{Cu}$ has been shown to increases amyloid deposits and $A ß$ oligomer aggregation, and decrease the amount of soluble Aß oligomer (Rebolledo et al., 2011). The increased Aß aggregation is associated with improvement in behavioral deficits and synaptic function. This protective effect is not attributable to the activation of the SKN-1/NRF2 phase II detoxification pathway (Rebolledo et al., 2011). Luo et al. noted that high $\mathrm{Cu}$ concentrations significantly increased the paralysis rate of the $\mathrm{Aß}(1-42)$ transgenic worms, whereas lower $\mathrm{Cu}$ concentrations decreased paralysis rate. ROS were identified to be responsible for the paralysis and the ROS induced by $\mathrm{A}(1-42)$ and $\mathrm{Cu}$ was mediated through sod-1, prdx-2, skn-1, hsp-60, and $h s p-16.2$ genes (Luo et al., 2011). The amyloid precursor protein (APP) of AD has a copper-binding domain (CuBD) located in the N-terminal cysteine-rich region that can strongly bind $\mathrm{Cu}$ (II) and reduce it to $\mathrm{Cu}(\mathrm{I})$. The CuBD of C. elegans, APL-1, protected against $\mathrm{Cu}$-mediated lipid peroxidation and neurotoxicity, therefore the $\mathrm{CuBD}$ of APP is predicted to play a role in detoxification of neuronal Cu (White et al., 2002; Cerpa et al., 2004).

\section{Cadmium (Cd)}

$\mathrm{Cd}$ is an environmental pollutant that has been classified as a category 1 human carcinogen (IARC, 1993). Cd exposure is associated with teratogenic and mutagenic responses (WHO, 1996). The major routes of human exposure include diet and cigarette smoke (EFSA, 2009). In C. elegans, Cd has been shown to alter behavior. It also resulted in decreased growth, life span and reproduction and affected feeding and movement (Popham and Webster, 1979; Boyd et al., 2010; Hoss et al., 2011; Hsu et al., 2012). Cd exposure was also shown to cause GABAergic neurodegeneration in worms. At low Cd concentration neuronal loss was observed, while at high Cd concentration axonal degeneration and neuronal loss, as well as reduced size of AVL, RMEs and RIS neurons was noted in fluorescently labeled GABAergic neurons (Du and Wang, 2009).

\section{Iron (Fe)}

The essential trace element Fe exists abundantly in the environment and is present in various enzymes and proteins. It has a central role in many essential cellular processes such as DNA synthesis, mitochondrial respiration, oxygen transport, and neurotransmitter synthesis (Cairo et al., 2002). Fe homeostasis has to be maintained within a small range because a dysregulation caused by Fe deficiency or overload leads to hematological, neurodegenerative and metabolic diseases (Dusek et al., 2012; Tandara and Salamunic, 2012). Genes involved in Fe and energy homeostasis in vertebrates are conserved in the nematode. These include aconitase, ferritin, divalent metal transporter-1 (DMT-1), frataxin, and Fe sulfur cluster assembly proteins. The Fe regulating protein1 (IRP-1) homolog (ACO-1) of C. elegans has aconitase activity and is post-translationally regulated by Fe. Although ACO-1 is predicted to be the IRP-1 homolog in C. elegans, it fails to bind to the ferritin mRNAs and no conserved Fe responsive elements have been found on ferritin mRNAs in C. elegans (Gourley et al., 2003).

In contrast, Kim et al. reported that aco- 1 and $f t n-1$ expression levels are regulated by Fe. Both aco- 1 and $f t n-1$ gene expression is inversely correlated. $f t n-1$ and $f t n-2$ are encoding ferritins in $C$. elegans (Kim et al., 2004). In mutant animals lacking ACO-1 and FTN-1, reduced lifespan has been observed, indicating that aco1 and $f t n-1$ are important for regulating Fe homeostasis. daf-16 mutants show decreased lifespan upon Fe treatment, suggesting that DAF-16 signaling might be also involved in Fe homeostasis (Kim et al., 2004). HIF-1 (hypoxia-inducible factor-1) is a negative regulator of ferritin transcription, inhibiting $f t n-1$ and $f t n-2$ transcription during Fe deficiency. Furthermore, the activation of the Fe uptake gene smf-3 (a homolog of DMT-1) by HIF-1 during Fe-deficiency (Romney et al., 2011) provides a mechanism to maintain sufficient Fe stock for growth and survival when Fe is limited in C. elegans.

Fe overload in worms causes phenotypic and behavioral defects as well as alteration the resistance to oxidative stress, characterized by reduced lifespan, body size, generation time, brood size, head thrash and body bend frequencies, as well as chemotaxis plasticity (Hu et al., 2008; Valentini et al., 2012). Several of these defects (body bend frequency and life span) were transferred from Fe-exposed C. elegans to their progeny (Hu et al., 2008). The adverse effects of Fe on locomotive behavior suggest that Fe might be involved in disruption of synaptic function between neurons and muscle cells. In C. elegans models of $A B$ toxicity, $\mathrm{Fe}$ was shown to possess high affinity for $A ß$. $A B$ accumulation in the $A ß$-expressing strain CL2006 resulted in Fe homeostasis disruption. In addition to increasing Fe content, $A ß$ has also been shown to increase ROS generation (Wan et al., 2011).

\section{Lead $(\mathbf{P b})$}

Lead is a pervasive environmental neurotoxicant; it is particularly toxic to developmental brains, causing long-term detrimental effects on learning, memory and behavior in children (Neal and Guilarte, 2010). Pb exposed C. elegans show severe abnormalities in their lifespan, development, locomotion, learning and memory behaviors (Ye et al., 2008; Zhang et al., 2010). Younger larva (L1, L2, L3) nematodes exhibited increased lethality and reproductive toxicity (brood size, generation time) compared to L4 stage or adult nematodes (Guo et al., 2009; Xing et al., 2009a). L3 larvae showed higher sensitivity in transgenerational behavioral and growth effects than older life stages (Yu et al., 2013). Neurodegeneration, as shown by neuronal loss and dorsal/ventral cord gaps is more pronounced in L1 larvae compared to older nematodes (Du and Wang, 2009; Xing et al., 2009b).

$\mathrm{Pb}$ exposure decreases thermotaxis behaviors in adult $C$. elegans. This behavior is mainly controlled by the AFD sensory neurons and it has been shown that $\mathrm{Pb}$ caused severe deficits in the structural properties of these neurons. Pre-treatment with antioxidants inhibited ROS elevation and mitochondrial dysfunction caused by $\mathrm{Pb}$ and prevented the induction of oxidative damage, severe deficits in thermotaxis and damage to the AFD 
sensory neurons (Wu et al., 2012). Vitamin E and mild UV radiation or a pre-treatment with heat shock increase the resistance of nematodes to $\mathrm{Pb}$ toxicity, ameliorating the effects on locomotion behaviors, stress response and memory deficits (Ye et al., 2008; Wang et al., 2010; Ye et al., 2010).

\section{Methylmercury (MeHg)}

Mercury ( $\mathrm{Hg})$ and methylmercury $(\mathrm{MeHg})$ are of greatest concern as $\mathrm{MeHg}$ is an ubiquitous environmental contaminant (Sanfeliu et al., 2003) and a major source of human exposure is associated with the consumption of seafood (Fitzgerald and Clarkson, 1991). McElwee et al. compared the toxicity of $\mathrm{HgCl}_{2}$ and $\mathrm{MeHgCl}$, noting the latter is significantly more toxic than $\mathrm{HgCl}_{2}$ when assessing feeding, movement and reproduction, and in its ability to increase the steady-state levels of stress response genes (McElwee and Freedman, 2011). Helmcke et al. showed that while lethality, pharyngeal, pumping, growth and development were affected in C. elegans, brood size, lifespan, trashing rate, and nervous system morphology were largely unaffected in response to $\mathrm{MeHg}$ exposure. Concerning $\mathrm{Hg}$ uptake in C. elegans, its concentrations are as high as those found in mammalian systems (Helmcke et al., 2009; Helmcke and Aschner, 2010). It is also confirmed that the involvement of oxidative stress in $\mathrm{MeHg}$ toxicity is through alterations in GSH levels, increasing expression of HSP and glutathione-S-transferase (Helmcke and Aschner, 2010). In mammals, Nrf-2 regulates oxidative stress response. The worm Nrf-2 homolog, SKN-1, is also expressed in C. elegans DA neurons and a reduction in $s k n-1$ gene expression increases $\mathrm{MeHg}$-induced DAergic neurodegeneration (VanDuyn et al., 2010).

\section{Manganese (Mn)}

The naturally abundant micronutrient $\mathrm{Mn}$ is an essential trace element and is of crucial importance as co-factor for a wide variety of enzymes, including arginase, pyruvate carboxylase, the antioxidant enzyme SOD, as well as enzymes involved in neurotransmitter synthesis and metabolism (Santamaria and Sulsky, 2010). An imbalance in Mn homeostasis caused by either Mn deficiency or overload is well known to cause severe CNS dysfunction, whereas Mn deficiency is because of its ubiquitous presence in food extremely rare. Therefore, several mechanisms are involved in maintaining the Mn homeostasis. The NRAMPs/divalent metal transporters play distinct roles in Mn transport and the identified C. elegans homologs (SMF-1, SMF-2, and SMF-3) have been characterized with corresponding roles in $\mathrm{Mn}$ homeostasis and sensitivity (Au et al., 2009; Bandyopadhyay et al., 2009; Settivari et al., 2009). The three SMFs differ in localization and function, and SFM-3 has to be shown as the major Mn transporter. A deletion of the $s m f-1$ or $s m f-3$ increased Mn tolerance against Mn-induced DAergic neurodegeneration with $s m f-3$ as the most resistant mutant, whereas the deletion of $s m f-2$ increases Mn sensitivity indicating the protective role of $s m f-2$ against $\mathrm{Mn}$ ( $\mathrm{Au}$ et al., 2009). The DA reuptake transporter, DAT-1, has also been associated in Mn toxicity and dysfunction sensitizes the worm to Mn neurotoxicity (Chen et al., 2006; Benedetto et al., 2010). In C. elegans PMR1, a P-type $\mathrm{Ca}^{2+/} \mathrm{Mn}^{2+}$ ATPase is involved in the regulation of $\mathrm{Ca}$ and $\mathrm{Mn}$ ions and PMR-1 knockdowns can render resistance to stresses, such as oxidative stress (Cho et al.,
2005; Bandyopadhyay et al., 2009). McColl et al. provide the first quantitative subcellular visualization of endogenous Mn concentrations in C. elegans identifying Mn enriched within specific cell types, especially intestinal cells (McColl et al., 2012).

Concerning $\mathrm{Mn}$ toxicity in C. elegans, it has been investigated that the anti- or pro-oxidative role for $\mathrm{Mn}$ is dependent on the Mn-concentration worms are exposed to (Lin et al., 2006). In case of Mn overload accelerated development, an increase in total fertility, reduced body and brood size and life span was observed (Lin et al., 2006; Xiao et al., 2009). Mn toxicity in C. elegans has been associated with increased ROS formation and glutathione production, head mitochondria membrane potential and DA neuronal death (Settivari et al., 2009; Benedetto et al., 2010). Benedetto et al. found that Mn-induced oxidative stress was dependent on the extracellular levels of DA, which was confirmed by using strains lacking functional DA receptors (DOP-1, 2,3 ) and the DA transporter (DAT-1) that regulate extracellular DA, and strains lacking vesicular monoamine transporter 2 (CAT-1 in worms) and tyrosine hydroxylase (CAT-2 in worms) that regulate intracellular DA levels. Decreased extracellular DA levels are protective against Mn toxicity (Benedetto et al., 2010). They identified NADPH dual-oxidase, BLI-3, potentiates the formation of RONS from DA-derived species obtained by the Mn (II) and extracellular DA exposure, while the bli-3 mutant a hyper-resistant phenotype of Mn toxicity showed which could be a potential therapeutic target against Mn toxicity (Benedetto et al., 2010). Consistent with the oxidative stress associated with Mn exposure, SKN-1 (antioxidant transcription factor contributing to protection against ROS; homolog of mammalian Nrf2) overexpression or nuclear relocalization of SKN-1 protects from Mn neurotoxicity indicating a beneficial strategies in limiting Mn toxicity (Benedetto et al., 2010). Prominent theories on neurodegeneration implicate further protein aggregation, including $\alpha$-synuclein. Recently suppression of $\alpha$-synuclein-induced toxicity has been demonstrated by expression of PARK9 encoding a putative P-type transmembrane ATPase (ATP13A2) protein (Gitler et al., 2009).

\section{Zinc (Zn)}

$\mathrm{Zn}$ is one of the most prevalent essential elements. It is a cofactor in many enzymes and transcription factors involved in several cellular processes and cellular signaling pathways (Shuttleworth and Weiss, 2011). Zinc deficiency as well as excess causes a wide spectrum of defects in multiple organ systems. Zn's role in memory, learning, neurogenesis, processes related to brain aging and neurological diseases have been extensively reviewed (Szewczyk et al., 2011).

In C. elegans, families of the CDFs (cation diffusion facilitators), ZIPs (Zrt- and Irt-like proteins) and MTs (metallothioneins) are involved in Zn metabolism. Deletion of MT-1 and MT-2 results in increased $\mathrm{Zn}$ accumulation, whilst $m t l-1$ knockout worms show heightened sensitivity to increased $\mathrm{Zn}$ level (Leszczyszyn et al., 2011). cdf-1 and sur-7 are both members of the CDF family, and mutations in either gene result in increased sensitivity to $\mathrm{Zn}$, indicating that both genes are necessary for $\mathrm{Zn}$ tolerance. However, sur-7 mutants were more tolerant than a $c d f-1$ mutant to increased $\mathrm{Zn}$ concentrations, suggesting functional 
differences between these two proteins (Yoder et al., 2004). In addition, mutations of haly-1, which encodes an enzyme converting histidine to uric acid, cause elevated levels of histidine and protect against Zn toxicity (Murphy et al., 2011). A lossof-function study of $c d f-1, c d f-2$, sur-7, and haly-1 showed that haly-1 promotes $\mathrm{Zn}$ resistance in the genetic backgrounds characterized by $\mathrm{Zn}$ sensitivity and functions in parallel to $c d f$ genes in modulating $\mathrm{Zn}$ sensitivity. Zn exposure in $C$. elegans results in multiple biological defects affecting life span, reproduction, locomotion behavior (head trash, body bend) and chemotaxis plasticity (Wang et al., 2007). The phenotypic and behavioral toxicities could be transferred from $\mathrm{Zn}$-exposed nematodes to their progeny (Yoder et al., 2004; Wang et al., 2007). While defects such as life span, generation time, brood size, and chemotaxis plasticity could be partially rescued in the progeny, no rescue phenomena could be observed for body sizes and the locomotion behaviors. In addition, it has been reported that the pesticide $\mathrm{Mn} / \mathrm{Zn}$-ethylenebis-dithiocarbamate promotes neurodegeneration in DAergic and GABAergic neurons (Guven et al., 1999; Negga et al., 2011, 2012; Harrison Brody et al., 2013).

\section{CONCLUSION}

C. elegans is a valuable model to study human neurological diseases due to conserved genome, low culture cost, short generation

\section{REFERENCES}

Ahringer, J. (2006). "Reverse Genetics," in Wormbook, ed The C. elegans Research Community, 10.1895/wormbook.1.47.1. Available online at: http://www.wormbook.org

Alkema, M. J., Hunter-Ensor, M., Ringstad, N., and Horvitz, H. R. (2005). Tyramine Functions independently of octopamine in the Caenorhabditis elegans nervous system. Neuron 46, 247-260.

Antoshechkin, I., and Sternberg, P. W. (2007). The versatile worm: genetic and genomic resources for Caenorhabditis elegans research. Nat. Rev. Genet. 8, 518-532.

Arredondo, M., and Nunez, M. T. (2005). Iron and copper metabolism. Mol. Aspects Med. 26, 313-327.

Au, C., Benedetto, A., Anderson, J., Labrousse, A., Erikson, K., Ewbank, J. J., et al. (2009). SMF-1, SMF2 and SMF-3 DMT1 orthologues regulate and are regulated differentially by manganese levels in $C$. elegans. PLoS ONE 4:e7792. doi: 10.1371/journal.pone.0007792

Bandyopadhyay, J., Song, H. O., Park, B. J., Singaravelu, G., Sun, J. L., Ahnn, J., et al. (2009). Functional assessment of Nramp-like metal transporters and manganese in Caenorhabditis elegans. Biochem. Biophys. Res. Commun. 390, 136-141.
Bany, I. A., Dong, M-Q, and Koelle, M. R. (2003). Genetic and cellular basis for acetylcholine inhibition of Caenorhabditis elegans egg-laying behavior. J. Neurosci. 23, 8060-8069.

Barbagallo, B., Prescott, H. A., Boyle, P., Climer, J., and Francis, M. M. (2010). A dominant mutation in a neuronal acetylcholine receptor subunit leads to motor neuron degeneration in Caenorhabditis elegans. J. Neurosci. 30, 13932-13942.

Bazopoulou, D., and Tavernarakis, N. (2009). The NemaGENETAG initiative: large scale transposon insertion gene-tagging in Caenorhabditis elegans. Genetica 137, 39-46.

Benedetto, A., Au, C., Avila, D. S., Milatovic, D., and Aschner, M. (2010). Extracellular dopamine potentiates mn-induced oxidative stress, lifespan reduction, and dopaminergic neurodegeneration in a BLI-3-dependent manner in Caenorhabditis elegans. PLoS Genet. 6:e1001084. doi: 10.1371/journal.pgen.1001084

Boyd, W. A., Smith, M. V., Kissling, G. E., and Freedman, J. H. (2010). Medium- and high-throughput screening of neurotoxicants using C. elegans. Neurotoxicol. Teratol. 32, 68-73.

Brandt, R., Gergou, A., Wacker, I., Fath, T., and Hutter, H. (2009). A Caenorhabditis elegans model of tau hyperphosphorylation: induction of developmental defects

cycle, transparent tissue and simple nervous system, together with well-developed tools. A solid number of nematode models related to human neurological disorders have already been developed, including AD (Miyasaka et al., 2005; Brandt et al., 2009), Parkinson's disease (Cao et al., 2005; Hamamichi et al., 2008), Huntington's disease (Parker et al., 2001; Caldwell et al., 2003), ALS (Vaccaro et al., 2012), and early-onset torsion dystonia (Cao et al., 2005; Chen et al., 2010). These disease models facilitate the study of metal-induced neurological toxicity and many novel discoveries have already been made in C. elegans to uncover the mechanisms of metals related human neurological disorders. Despite of these advantages, limitations of the nematode system need to be considered. For example, some genes and signaling pathways inherent to mammals (such as $\alpha$-synuclein and $A \beta$ discussed above) are missing in this model. In sum, C. elegans provide a valuable platform for exploratory study of human neurological diseases by providing mechanistic information on processes inherent to neurodegenerative disorders.

\section{ACKNOWLEDGMENTS}

The authors acknowledge partial support for this review from the National Institute of Environmental Health Sciences (R01 ES 10563, P30 ES 00267, T32 ES 007028), The Josef Schormüller Award and the DFG (BO 4103/1-1).

by transgenic overexpression of Alzheimer's disease-like modified tau. Neurobiol. Aging 30, 22-33.

Brockie, P. J., Madsen, D. M., Zheng, Y., Mellem, J., and Maricq, A. V. (2001). Differential expression of glutamate receptor subunits in the nervous system of Caenorhabditis elegans and their regulation by the homeodomain protein UNC-42. J. Neurosci. 21, 1510-1522.

Broster, B. S., and Rankin, C. H. (1994). Effects of changing interstimulus interval during habituation in Caenorhabditis elegans. Behav. Neurosci. 108, 1019-1029.

Cairo, G., Recalcati, S., Pietrangelo, A., and Minotti, G. (2002). The iron regulatory proteins: targets and modulators of free radical reactions and oxidative damage. Free Radic. Biol. Med. 32, 1237-1243.

Calafato, S., Swain, S., Hughes, S., Kille, P., and Sturzenbaum, S. R. (2008). Knock down of Caenorhabditis elegans cutc-1 exacerbates the sensitivity toward high levels of copper. Toxicol. Sci. 106, 384-391.

Caldwell, G. A., Cao, S., Sexton, E. G., Gelwix, C. C., Bevel, J. P., and Caldwell, K. A. (2003). Suppression of polyglutamine-induced protein aggregation in Caenorhabditis elegans by torsin proteins. Hum. Mol. Genet. 12, 307-319.

Cao, S., Gelwix, C. C., Caldwell, K. A., and Caldwell, G. A. (2005). Torsin-mediated protection from cellular stress in the dopaminergic neurons of Caenorhabditis elegans. J. Neurosci. 25, 3801-3812.

Cerpa, W. F., Barria, M. I., Chacon, M. A., Suazo, M., Gonzalez, M., Opazo, C., et al. (2004). The Nterminal copper-binding domain of the amyloid precursor protein protects against $\mathrm{Cu} 2+$ neurotoxicity in vivo. FASEB J. 18, 1701-1703.

Chen, M. K., Lee, J. S., McGlothan, J. L., Furukawa, E., Adams, R. J., Alexander, M., et al. (2006). Acute manganese administration alters dopamine transporter levels in the non-human primate striatum. Neurotoxicology 27, 229-236.

Chen, P., Burdette, A. J., Porter, J. C., Ricketts, J. C., Fox, S. A., Nery, F. C., et al. (2010). The early-onset torsion dystonia-associated protein, torsinA, is a homeostatic regulator of endoplasmic reticulum stress response. Hum. Mol. Genet. 19, 3502-3515.

Cho, J. H., Ko, K. M., Singaravelu, G., and Ahnn, J. (2005). Caenorhabditis elegans PMR1, a P-type calcium ATPase, is important for calcium/manganese homeostasis and oxidative stress response. FEBS Lett. 579, 778-782.

Cinar, H., Keles, S., and Jin, Y. (2005). Expression profiling of GABAergic motor neurons in Caenorhabditis elegans. Curr. Biol. 15, 340-346.

Colbert, H. A., and Bargmann, C. I. (1995). Odorant-specific adaptation 
pathways generate olfactory plasticity in C. elegans. Neuron 14, 803-812.

Diaz-Veliz, G., Paris, I., Mora, S., Raisman-Vozari, R., and SeguraAguilar, J. (2008). Copper neurotoxicity in rat substantia nigra and striatum is dependent on DTdiaphorase inhibition. Chem. Res. Toxicol. 21, 1180-1185.

Du, M., and Wang, D. (2009). The neurotoxic effects of heavy metal exposure on GABAergic nervous system in nematode Caenorhabditis elegans. Environ. Toxicol. Pharmacol. 27, 314-320.

Dusek, P., Jankovic, J., and Le, W. (2012). Iron dysregulation in movement disorders. Neurobiol. Dis. 46, $1-18$.

Earls, L. R., Hacker, M. L., Watson, J. D., and Miller, D. M. (2010). Coenzyme $\mathrm{Q}$ protects Caenorhabditis elegans GABA neurons from calciumdependent degeneration. Proc. Natl. Acad. Sci. U.S.A. 107, 14460-14465.

EFSA. (2009). Cadmium in food. Scientific opinion of the panel on contaminants in the food chain. EFSA J. 980, 1-139.

Estevez, A. O., Mueller, C. L., Morgan, K. L., Szewczyk, N. J., Teece, L., Miranda-Vizuete, A., et al. (2012). Selenium induces cholinergic motor neuron degeneration in Caenorhabditis elegans. Neurotoxicology 33, 1021-1032.

Fitzgerald, W. F., and Clarkson, T. W. (1991). Mercury and monomethylmercury: present and future concerns. Environ. Health Perspect. 96, 159-166.

Frokjaer-Jensen, C., Davis, M. W., Hollopeter, G., Taylor, J., Harris, T. W., Nix, P., et al. (2010). Targeted gene deletions in $C$. elegans using transposon excision. Nat. Methods 7, 451-453.

Gitler, A. D., Chesi, A., Geddie, M. L., Strathearn, K. E., Hamamichi, S., Hill, K. J.,et al. (2009). Alphasynuclein is part of a diverse and highly conserved interaction network that includes PARK9 and manganese toxicity. Nat. Genet. 41 , 308-315.

Gourley, B. L., Parker, S. B., Jones, B. J., Zumbrennen, K. B., and Leibold, E. A. (2003). Cytosolic aconitase and ferritin are regulated by iron in Caenorhabditis elegans. J. Biol. Chem. 278, 3227-3234.

Groves, P. M., and Thompson, R. F. (1970). Habituation: a dual-process theory. Psychol. Rev. 77, 419-450.

Guo, Y., Yang, Y., and Wang, D. (2009). Induction of reproductive deficits in nematode Caenorhabditis elegans exposed to metals at different developmental stages. Reprod. Toxicol. 28, 90-95.

Guven, K., Power, R. S., Avramides, S., Allender, R., and de Pomerai, D. I. (1999). The toxicity of dithiocarbamate fungicides to soil nematodes, assessed using a stress-inducible transgenic strain of Caenorhabditis elegans. J. Biochem. Mol. Toxicol. 13, 324-333.

Halatek, T., Sinczuk-Walczak, H., and Rydzynski, K. (2005). Prognostic significance of low serum levels of Clara cell phospholipid-binding protein in occupational aluminium neurotoxicity. J. Inorg. Biochem. 99, 1904-1911.

Hamamichi, S., Rivas, R. N., Knight, A. L., Cao, S., Caldwell, K. A., and Caldwell, G. A. (2008). Hypothesis-based RNAi screening identifies neuroprotective genes in a Parkinson's disease model. Proc. Natl. Acad. Sci. U.S.A. 105, 728-733.

Harada, H., Kurauchi, M., Hayashi, R., and Eki, T. (2007). Shortened lifespan of nematode Caenorhabditis elegans after prolonged exposure to heavy metals and detergents. Ecotoxicol. Environ. Saf. 66, 378-383.

Harrington, A. J., Yacoubian, T. A., Slone, S. R., Caldwell, K. A., and Caldwell, G. A. (2012). Functional analysis of VPS41-mediated neuroprotection in Caenorhabditis elegans and mammalian models of Parkinson's disease. J. Neurosci. 32, 2142-2153.

Harrison Brody, A., Chou, E., Gray, J. M., Pokyrwka, N. J., and RaleySusman, K. M. (2013). Mancozebinduced behavioral deficits precede structural neural degeneration. Neurotoxicology 34, 74-81.

Helmcke, K. J., and Aschner, M. (2010). Hormetic effect of methylmercury on Caenorhabditis elegans. Toxicol. Appl. Pharmacol. 248, 156-164.

Helmcke, K. J., Avila, D. S., and Aschner, M. (2010). Utility of Caenorhabditis elegans in high throughput neurotoxicological research. Neurotoxicol. Teratol. 32, 62-67.

Helmcke, K. J., Syversen, T., Miller, D. M. 3rd., and Aschner, M. (2009). Characterization of the effects of methylmercury on Caenorhabditis elegans. Toxicol. Appl. Pharmacol. 240, 265-272.

Hills, T., Brockie, P. J., and Maricq, A. V. (2004). Dopamine and glutamate control area-restricted search behavior in Caenorhabditis elegans. J. Neurosci. 24, 1217-1225.

Horvitz, H. R., Chalfie, M., Trent, C., Sulston, J. E., and Evans, P. D. (1982). Serotonin and octopamine in the nematode Caenorhabditis elegans. Science 216, 1012-1014.

Hoss, S., Schlottmann, K., and Traunspurger, W. (2011). Toxicity of ingested cadmium to the nematode Caenorhabditis elegans. Environ. Sci. Technol. 45, 10219-10225.

Hsu, P. C., O'Callaghan, M., AlSalim, N., and Hurst, M. R. (2012). Quantum dot nanoparticles affect the reproductive system of Caenorhabditis elegans. Environ. Toxicol. Chem. 31, 2366-2374.

Hu, Y. O., Wang, Y., Ye, B. P., and Wang, D. Y. (2008). Phenotypic and behavioral defects induced by iron exposure can be transferred to progeny in Caenorhabditis elegans. Biomed. Environ. Sci. 21, 467-473.

IARC. (1993). "Cadmium and certain cadmium compounds," in IARC Monographs on the EValuation the Carcinogenic Risk of Chemicals to Humans. Beryllium Cadmium, Mercury and Exposures in the Glass Manufacturing Industry (Lyon: IARC), 119-146, 210-236,

Isik, M., and Berezikov, E. (2013). Biolistic transformation of Caenorhabditis elegans. Methods Mol. Biol. 940, 77-86.

Jayanthi, L. D., Apparsundaram, S., Malone, M. D., Ward, E., Miller, D. M., Eppler, M., et al. (1998). The Caenorhabditis elegans gene T23G5.5 encodes an antidepressantand cocaine-sensitive dopamine transporter. Mol. Pharmacol. 54, 601-609.

Jin, Y., Hoskins, R., and Horvitz, H. R. (1994). Control of type-D GABAergic neuron differentiation by C. elegans UNC-30 homeodomain protein. Nature 372, 780-783.

Jin, Y., Jorgensen, E., Hartwieg, E., and Horvitz, H. R. (1999). The Caenorhabditis elegans gene unc- 25 encodes glutamic acid decarboxylase and is required for synaptic transmission but not synaptic development. J. Neurosci. 19, 539-548.

Kage-Nakadai, E., Kobuna, H., Funatsu, O., Otori, M., GengyoAndo, K., Yoshina, S., et al. (2012). Single/low-copy integration of transgenes in Caenorhabditis elegans using an ultraviolet trimethylpsoralen method. BMC Biotechnol. 12:1. doi: 10.1186/1472-6750-12-1

Kennedy, S., Wang, D., and Ruvkun, G. (2004). A conserved siRNAdegrading RNase negatively regulates RNA interference in C. elegans. Nature 427, 645-649.

Kim, Y. I., Cho, J. H., Yoo, O. J., and Ahnn, J. (2004). Transcriptional regulation and life-span modulation of cytosolic aconitase and ferritin genes in C.elegans. J. Mol. Biol. 342, 421-433.

Kraemer, B. C., Zhang, B., Leverenz, J. B., Thomas, J. H., Trojanowski, J. Q., and Schellenberg, G. D. (2003). Neurodegeneration and defective neurotransmission in a Caenorhabditis elegans model of tauopathy. Proc. Natl. Acad. Sci. U.S.A. 100, 9980-9985.

Lee, J., Jee, C., and McIntire, S. L. (2009). Ethanol preference in C. elegans. Genes Brain Behav. 8, 578-585.

Lee, R. Y. N., Sawin, E. R., Chalfie, M., Horvitz, H. R., and Avery, L. (1999). EAT-4, a homolog of a mammalian sodium-dependent inorganic phosphate cotransporter, is necessary for glutamatergic neurotransmission in Caenorhabditis elegans. J. Neurosci. 19, 159-167.

Leszczyszyn, O. I., Zeitoun-Ghandour, S., Sturzenbaum, S. R., and Blindauer, C. A. (2011). Tools for metal ion sorting: in vitro evidence for partitioning of zinc and cadmium in C. elegans metallothionein isoforms. Chem. Commun. (Camb.) 47, 448-450.

Li, Y., Yu, S., Wu, Q., Tang, M., Pu, Y., and Wang, D. (2012). Chronic Al2O3-nanoparticle exposure causes neurotoxic effects on locomotion behaviors by inducing severe ROS production and disruption of ROS defense mechanisms in nematode Caenorhabditis elegans. J. Hazard. Mater. 219-220, 221-230.

Lin, Y. T., Hoang, H., Hsieh, S. I., Rangel, N., Foster, A. L., Sampayo, J. N., et al. (2006). Manganous ion supplementation accelerates wild type development, enhances stress resistance, and rescues the life span of a short-lived Caenorhabditis elegans mutant. Free Radic. Biol. Med. 40, 1185-1193.

Liu, K. S., and Sternberg, P. W. (1995). Sensory regulation of male mating behavior in caenorhabditis elegans. Neuron 14, 79-89.

Loer, C. M., and Kenyon, C. J. (1993). Serotonin-deficient mutants and male mating behavior in the nematode Caenorhabditis elegans. J. Neurosci. 13, 5407-5417.

Luo, Y., Zhang, J., Liu, N., and Zhao, B. (2011). Copper ions influence the toxicity of beta-amyloid(1-42) in a concentration-dependent manner in a Caenorhabditis elegans model of Alzheimer's disease. Sci. China Life Sci. 54, 527-534.

Mano, I., Straud, S., and Driscoll, M. (2007). Caenorhabditis elegans glutamate transporters influence synaptic function and behavior at sites distant from the synapse. J. Biol. Chem. 282, 34412-34419. 
Martinez-Finley, E. J., and Aschner, M. (2011). Revelations from the nematode Caenorhabditis elegans on the complex interplay of metal toxicological mechanisms. J. Toxicol. 2011:895236. doi: 10.1155/2011/895236

McColl, G., James, S. A., Mayo, S., Howard, D. L., Ryan, C. G., Kirkham, R., et al. (2012). Caenorhabditis elegans maintains highly compartmentalized cellular distribution of metals and steep concentration gradients of manganese. PLoS ONE 7:e32685. doi: 10.1371/journal.pone.0032685

McElwee, M. K., and Freedman, J. H. (2011). Comparative toxicology of mercurials in Caenorhabditis elegans. Environ. Toxicol. Chem. 30, 2135-2141.

McIntire, S. L., Reimer, R. J., Schuske, K., Edwards, R. H., Jorgensen, E. M. (1997). Identification and characterization of the vesicular GABA transporter. Nature 389, 870-876.

McKay, J. P., Raizen, D. M., Gottschalk, A., Schafer, W. R., and Avery, L. (2004). eat- 2 and eat-18 are required for nicotinic neurotransmission in the Caenorhabditis elegans pharynx. Genetics 166, 161-169.

McLntire, S. L., Jorgensen, E., and Horvitz, H. R. (1993). Genes required for GABA function in Caenorhabditis elegans. Nature 364, 334-337.

Mellem, J. E., Brockie, P. J., Zheng, Y., Madsen, D. M., and Maricq, A. V. (2002). Decoding of polymodal sensory stimuli by postsynaptic glutamate receptors in C. elegans. Neuron 36, 933-944.

Mendel, J., Korswagen, H., Liu, K., Hajdu-Cronin, Y., Simon, M., Plasterk, R. H., et al. (1995). Participation of the protein Go in multiple aspects of behavior in $C$. elegans. Science 267, 1652-1655.

Miller, D. M. 3rd., Desai, N. S., Hardin, D. C., Piston, D. W., Patterson, G. H., Fleenor, J., et al. (1999). Twocolor GFP expression system for $C$. elegans. BioTechniques 26, 914-918. 920-921.

Miyasaka, T., Ding, Z., Gengyo-Ando, K., Oue, M., Yamaguchi, H., Mitani, S., et al. (2005). Progressive neurodegeneration in C. elegans model of tauopathy. Neurobiol. Dis. 20, 372-383.

Mocko, J. B., Kern, A., Moosmann, B., Behl, C., and Hajieva, P. (2010). Phenothiazines interfere with dopaminergic neurodegeneration in Caenorhabditis elegans models of Parkinson's disease. Neurobiol. Dis. 40, 120-129.
Mullen, G. P., Mathews, E. A., Vu, M. H., Hunter, J. W., Frisby, D. L., Duke, A., et al. (2007). Choline transport and de novo choline synthesis support acetylcholine biosynthesis in Caenorhabditis elegans cholinergic neurons. Genetics 177, 195-204.

Murphy, J. T., Bruinsma, J. J., Schneider, D. L., Collier, S., Guthrie, J., Chinwalla, A., et al. (2011). Histidine protects against zinc and nickel toxicity in Caenorhabditis elegans. PLoS Genet. 7:e1002013. doi: 10.1371/journal.pgen.1002013

Nass, R., Hall, D. H., Miller, D. M., and Blakely, R. D. (2002). Neurotoxininduced degeneration of dopamine neurons in Caenorhabditis elegans. Proc. Natl. Acad. Sci. U.S.A. 99, 3264-3269.

Neal, A. P., and Guilarte, T. R. (2010). Molecular neurobiology of lead $(\mathrm{Pb}(2+))$ : effects on synaptic function. Mol. Neurobiol. 42, 151-160.

Negga, R., Rudd, D. A., Davis, N. S., Justice, A. N., Hatfield, H. E., Valente, A. L., et al. (2011). Exposure to $\mathrm{Mn} / \mathrm{Zn}$ ethylene-bisdithiocarbamate and glyphosate pesticides leads to neurodegeneration in Caenorhabditis elegans. Neurotoxicology 32, 331-341.

Negga, R., Stuart, J. A., Machen, M. L., Salva, J., Lizek, A. J., Richardson, S. J., et al. (2012). Exposure to glyphosateand/or Mn/Zn-ethylene-bisdithiocarbamate-containing pesticides leads to degeneration of gamma-aminobutyric acid and dopamine neurons in Caenorhabditis elegans. Neurotox. Res. 21, 281-290.

Niacaris, T., and Avery, L. (2003). Serotonin regulates repolarization of the C. elegans pharyngeal muscle. J. Exp. Biol. 206, 223-231.

Page, K. E., White, K. N., McCrohan, C. R., Killilea, D. W., and Lithgow, G. J. (2012). Aluminium exposure disrupts elemental homeostasis in Caenorhabditis elegans. Metallomics 4, 512-522.

Parker, J. A., Connolly, J. B., Wellington, C., Hayden, M., Dausset, J., and Neri, C. (2001). Expanded polyglutamines in Caenorhabditis elegans cause axonal abnormalities and severe dysfunction of PLM mechanosensory neurons without cell death. Proc. Natl. Acad. Sci. U.S.A. 98, 13318-13323.

Popham, J. D., and Webster, J. M. (1979). Cadmium toxicity in the free-living nematode, Caenorhabditis elegans. Environ. Res. 20, 183-191.
Praitis, V., Casey, E., Collar, D., and Austin, J. (2001). Creation of lowcopy integrated transgenic lines in Caenorhabditis elegans. Genetics $157,1217-1226$.

Praitis, V., and Maduro, M. F. (2011) Transgenesis in C. elegans. Methods Cell Biol. 106, 161-185.

Prohaska, J. R. (2000). Long-term functional consequences of malnutrition during brain development: copper. Nutrition 16, 502-504.

$\mathrm{Pu}$, P., and Weidong, L. (2008). Dopamine neuron degeneration induced by MPP+ is independent of CED-4 pathway in Caenorhabditis elegans. Cell Res. 18, 978-981.

Rebolledo, D. L., Aldunate, R., Kohn, R., Neira, I., Minniti, A. N., and Inestrosa, N. C. (2011). Copper reduces Abeta oligomeric species and ameliorates neuromuscular synaptic defects in a $C$. elegans model of inclusion body myositis. J. Neurosci. 31, 10149-10158.

Rogers, C. M., Franks, C. J., Walker, R. J., Burke, J. F., and Holden-Dye, L. (2001). Regulation of the pharynx of Caenorhabditis elegans by 5HT, octopamine, and FMRFamidelike neuropeptides. J. Neurobiol. 49, 235-244.

Romney, S. J., Newman, B. S., Thacker C., and Leibold, E. A. (2011) HIF-1 regulates iron homeostasis in Caenorhabditis elegans by activation and inhibition of genes involved in iron uptake and storage. PLoS Genet. 7:e1002394. doi: 10.1371/journal.pgen.1002394

Rose, J. K., Kaun, K. R., Chen, S. H., and Rankin, C. H. (2003). GLR1 , a non-NMDA glutamate receptor homolog, is critical for long-term memory in Caenorhabditis elegans. J. Neurosci. 23, 9595-9599.

Rose, J. K., and Rankin, C. H. (2001). Analyses of habituation in Caenorhabditis elegans. Learn. Mem. 8, 63-69.

Ruan, Q., Harrington, A. J., Caldwell, K. A., Caldwell, G. A., and Standaert, D. G. (2010). VPS41, a protein involved in lysosomal trafficking, is protective in Caenorhabditis elegans and mammalian cellular models of Parkinson's disease. Neurobiol. Dis. 37, 330-338.

Sanfeliu, C., Sebastia, J., Cristofol, R. and Rodriguez-Farre, E. (2003). Neurotoxicity of organomercurial compounds. Neurotox. Res. 5, 283-305.

Santamaria, A. B., and Sulsky, S. I. (2010). Risk assessment of an essential element: manganese. J. Toxicol. Environ. Health A 73, 128-155.
Sanyal, S., Wintle, R. F., Kindt, K. S., Nuttley, W. M., Arvan, R., Fitzmaurice, P., et al. (2004). Dopamine modulates the plasticity of mechanosensory responses in Caenorhabditis elegans. EMBO J. 23, 473-482.

Sawin, E. R., Ranganathan, R., and Horvitz, H. R. (2000). C. elegans locomotory rate is modulated by the environment through a dopaminergic pathway and by experience through a serotonergic pathway. Neuron 26, 619-631.

Segalat, L., Elkes, D., and Kaplan, J. (1995). Modulation of serotonincontrolled behaviors by Go in Caenorhabditis elegans. Science 267, 1648-1651.

Settivari, R., Levora, J., and Nass, R. (2009). The divalent metal transporter homologues SMF-1/2 mediate dopamine neuron sensitivity in caenorhabditis elegans models of manganism and parkinson disease. J. Biol. Chem. 284, 35758-35768.

Shih, J. D., and Hunter, C. P. (2011). SID-1 is a dsRNA-selective dsRNAgated channel. RNA 17, 1057-1065.

Shuttleworth, C. W., and Weiss, J. H. (2011). Zinc: new clues to diverse roles in brain ischemia. Trends Pharmacol. Sci. 32, 480-486.

Simmer, F., Tijsterman, M., Parrish, S., Koushika, S. P., Nonet, M. L., Fire, A., et al. (2002). Loss of the putative RNA-directed RNA polymerase RRF-3 makes C. elegans hypersensitive to RNAi. Curr. Biol. 12, 1317-1319.

Sulston, J., Dew, M., and Brenner, S. (1975). Dopaminergic neurons in the nematode Caenorhabditis elegans. J. Comp. Neurol. 163, 215-226.

Sze, J. Y., Victor, M., Loer, C., Shi, Y., and Ruvkun, G. (2000). Food and metabolic signalling defects in a Caenorhabditis elegans serotoninsynthesis mutant. Nature 403, 560-564.

Szewczyk, B., Kubera, M., and Nowak, G. (2011). The role of zinc in neurodegenerative inflammatory pathways in depression. Prog. Neuropsychopharmacol. Biol. Psychiatry 35, 693-701.

Tabara, H., Grishok, A., and Mello, C. C. (1998). RNAi in C. elegans: soaking in the genome sequence. Science 282, 430-431.

Taly, A. B., Meenakshi-Sundaram, S., Sinha, S., Swamy, H. S., and Arunodaya, G. R. (2007). Wilson disease: description of 282 patients evaluated over 3 decades. Medicine (Baltimore) 86, 112-121.

Tandara, L., and Salamunic, I. (2012). Iron metabolism: current facts and 
future directions. Biochem. Med. (Zagreb) 22, 311-328.

Thomas, J. H. (1990). Genetic analysis of defecation in Caenorhabditis elegans. Genetics 124, 855-872.

Titus, K., and Michael, O. H. (2006). Finding function in novel targets: $C$. elegans as a model organism. Nat. Rev. Drug Discov. 5, 387-399.

Toth, M. L., Melentijevic, I., Shah, L., Bhatia, A., Lu, K., Talwar, A., et al. (2012). Neurite sprouting and synapse deterioration in the aging Caenorhabditis elegans nervous system. J. Neurosci. 32, 8778-8790.

Vaccaro, A., Tauffenberger, A., Aggad, D., Rouleau, G., Drapeau, P., and Parker, J. A. (2012). Mutant TDP43 and FUS cause age-dependent paralysis and neurodegeneration in C. elegans. PLoS ONE 7:e31321. doi: 10.1371/journal.pone.0031321

Valentini, S., Cabreiro, F., Ackerman, D., Alam, M. M., Kunze, M. B., Kay, C. W., et al. (2012). Manipulation of in vivo iron levels can alter resistance to oxidative stress without affecting ageing in the nematode C. elegans. Mech. Ageing Dev. 133, 282-290.

VanDuyn, N., Settivari, R., LeVora, J., Zhou, S., Unrine, J., and Nass, R. (2013). The metal transporter SMF-3/DMT-1 mediates aluminum-induced dopamine neuron degeneration. J. Neurochem. 124, 147-157.

VanDuyn, N., Settivari, R., Wong, G., and Nass, R. (2010). SKN-1/Nrf2 inhibits dopamine neuron degeneration in a Caenorhabditis elegans model of methylmercury toxicity. Toxicol. Sci. 118, 613-624.

Ved, R., Saha, S., Westlund, B., Perier, C., Burnam, L., Sluder, A., et al. (2005). Similar patterns of mitochondrial vulnerability and rescue induced by genetic modification of alpha-synuclein, parkin, and DJ-1 in Caenorhabditis elegans. J. Biol. Chem. 280, 42655-42668.

Verstraeten, S. V., Aimo, L., and Oteiza, P. I. (2008). Aluminium and lead: molecular mechanisms of brain toxicity. Arch. Toxicol. 82, 789-802.

Waggoner, L. E., Zhou, G. T., Schafer, R. W., and Schafer, W. R. (1998). Control of alternative behavioral states by serotonin in Caenorhabditis elegans. Neuron 21, 203-214.

Wan, L., Nie, G., Zhang, J., Luo, Y., Zhang, P., Zhang, Z., et al. (2011). beta-Amyloid peptide increases levels of iron content and oxidative stress in human cell and Caenorhabditis elegans models of Alzheimer disease. Free Radic. Biol. Med. 50, 122-129.
Wang, D., Kennedy, S., Conte, D. Jr., Kim, J. K., Gabel, H. W., Kamath, R. S., et al. (2005). Somatic misexpression of germline $\mathrm{P}$ granules and enhanced RNA interference in retinoblastoma pathway mutants. Nature 436, 593-597.

Wang, D., Liu, P., and Xing, X. (2010). Pre-treatment with mild UV irradiation increases the resistance of nematode Caenorhabditis elegans to toxicity on locomotion behaviors from metal exposure. Environ. Toxicol. Pharmacol. 29, 213-222.

Wang, D., Shen, L., and Wang, Y. (2007). The phenotypic and behavioral defects can be transferred from zinc-exposed nematodes to their progeny. Environ. Toxicol. Pharmacol. 24, 223-230.

Wang, D. Y., Yang, Y. C., and Wang, Y. (2009). [Aluminium toxicosis causing transferable defects from exposed animals to their progeny in Caenorhabditis elegans]. Zhonghua Yu Fang Yi Xue Za Zhi 43, 45-51.

Weinshenker, D., Garriga, G., and Thomas, J. (1995). Genetic and pharmacological analysis of neurotransmitters controlling egg laying in C. elegans. J. Neurosci. 15, 6975-6985.

White, A. R., Multhaup, G., Galatis, D., McKinstry, W. J., Parker, M. W., Pipkorn, R., et al. (2002). Contrasting, species-dependent modulation of copper-mediated neurotoxicity by the Alzheimer's disease amyloid precursor protein. J. Neurosci. 22, 365-376.

White, J. G., Southgate, E., Thomson, J. N., and Brenner, S. (1986). The structure of the nervous system of the nematode Caenorhabditis elegans. Philos. Trans. R. Soc. Lond. B Biol. Sci. 314, $1-340$.

WHO. (1996). "Guidelines for drinking-water quality, 2nd Edn.," in Health Criteria and Other Supporting Information, Vol. 2. (Geneva: World Health Organization).

Winnier, A. R., Meir, J. Y., Ross, J. M., Tavernarakis, N., Driscoll, M., Ishihara, T., et al. (1999). UNC-4/UNC-37-dependent repression of motor neuron-specific genes controls synaptic choice in Caenorhabditis elegans. Genes Dev. 13, 2774-2786.

WormAtlas. (2002). eds. Z. F. Altun, L. A. Herndon, C. Crocker, R. Lints, and D. H. Hall. Available online at: http://www.wormatlas.org

WormAtlas. (2003). eds. Z. F. Altun, L. A. Herndon, C. Crocker, R. Lints, and D. H. Hall. Available online at: http://www.wormatlas.org

WormAtlas. (2004). eds. Z. F. Altun, L. A. Herndon, C. Crocker, R. Lints, and D. H. Hall. Available online at: http://www.wormatlas.org

WormAtlas. (2005). eds. Z. F. Altun, L. A. Herndon, C. Crocker, R. Lints, and D. H. Hall. Available online at: http://www.wormatlas.org

WormAtlas. (2006). eds. Z. F. Altun, L. A. Herndon, C. Crocker, R. Lints, and D. H. Hall. Available online at: http://www.wormatlas.org

WormAtlas. (2007). eds. Z. F. Altun, L. A. Herndon, C. Crocker, R. Lints, and D. H. Hall. Available online at: http://www.wormatlas.org

WormAtlas. (2008). eds. Z. F. Altun, L. A. Herndon, C. Crocker, R. Lints, and D. H. Hall. Available online at: http://www.wormatlas.org

WormAtlas. (2009). eds. Z. F. Altun, L. A. Herndon, C. Crocker, R. Lints, and D. H. Hall. Available online at: http://www.wormatlas.org

WormBase. (2013). release WS236. Available online at: http://www. wormbase.org

Wu, Q., Liu, P., Li, Y., Du, M., Xing, X., and Wang, D. (2012). Inhibition of ROS elevation and damage to mitochondrial function prevents leadinduced neurotoxic effects on structures and functions of AFD neurons in Caenorhabditis elegans. J. Environ. Sci. (China) 24, 733-742.

Xiao, J., Rui, Q., Guo, Y., Chang, X., and Wang, D. (2009). Prolonged manganese exposure induces severe deficits in lifespan, development and reproduction possibly by altering oxidative stress response in Caenorhabditis elegans. J. Environ. Sci. (China) 21, 842-848.

Xing, X., Rui, Q., and Wang, D. (2009a). Lethality toxicities induced by metal exposure during development in nematode Caenorhabditis elegans. Bull. Environ. Contam. Toxicol. 83, 530-536.

Xing, X. J., Rui, Q., Du, M., and Wang, D. Y. (2009b). Exposure to lead and mercury in young larvae induces more severe deficits in neuronal survival and synaptic function than in adult nematodes. Arch. Environ. Contam. Toxicol. 56, 732-741.

Yang, M. S., Wong, H. F., and Yung, K. L. (1998). Determination of endogenous trace metal contents in various mouse brain regions after prolonged oral administration of aluminum chloride. J. Toxicol. Environ. Health A 55, 445-453.

Ye, B., Rui, Q., Wu, Q., and Wang, D. (2010). Metallothioneins are required for formation of cross-adaptation response to neurobehavioral toxicity from lead and mercury exposure in nematodes. PLOS ONE 5:e14052. doi: 10.1371/journal.pone.0014052

Ye, H., Ye, B., and Wang, D. (2008). Trace administration of vitamin E can retrieve and prevent UV-irradiation- and metal exposure-induced memory deficits in nematode Caenorhabditis elegans. Neurobiol. Learn. Mem. 90, 10-18.

Yoder, J. H., Chong, H., Guan, K. L., and Han, M. (2004). Modulation of KSR activity in Caenorhabditis elegans by $\mathrm{Zn}$ ions, PAR-1 kinase and PP2A phosphatase. EMBO J. 23, 111-119.

Yu, S., Rui, Q., Cai, T., Wu, Q., Li, Y., and Wang, D. (2011). Close association of intestinal autofluorescence with the formation of severe oxidative damage in intestine of nematodes chronically exposed to $\mathrm{Al}(2) \mathrm{O}(3)$-nanoparticle. Environ. Toxicol. Pharmacol. 32, 233-241.

Yu, Z., Chen, X., Zhang, J., Wang, R., and Yin, D. (2013). Transgenerational effects of heavy metals on L3 larva of Caenorhabditis elegans with greater behavior and growth inhibitions in the progeny. Ecotoxicol. Environ. Saf. 88, 178-184.

Zhang, Y., Ye, B., and Wang, D. (2010). Effects of metal exposure on associative learning behavior in nematode Caenorhabditis elegans. Arch. Environ. Contam. Toxicol. 59, 129-136.

Conflict of Interest Statement: The authors declare that the research was conducted in the absence of any commercial or financial relationships that could be construed as a potential conflict of interest.

Received: 26 February 2013; paper pending published: 11 March 2013; accepted: 05 April 2013; published online: 20 May 2013.

Citation: Chen P, Martinez-Finley EJ, Bornhorst J, Chakraborty $S$ and Aschner M (2013) Metal-induced neurodegeneration in C. elegans. Front. Aging Neurosci. 5:18. doi: 10.3389/fnagi. 2013.00018

Copyright (C) 2013 Chen, MartinezFinley, Bornhorst, Chakraborty and Aschner. This is an open-access article distributed under the terms of the Creative Commons Attribution License, which permits use, distribution and reproduction in other forums, provided the original authors and source are credited and subject to any copyright notices concerning any third-party graphics etc. 